\title{
Tratamentos tópicos de melasma
}

\section{Topical melasma treatments}

Allyne Resplande Oliveira ${ }^{1}$, Dayane Borges de Morais Barbosa ${ }^{1}$, Elaine Mayra

Teixeira Pereira², Sávia Denise Silva Carlotto Herrera ${ }^{3}$

\section{RESUMO}

O melasma é um distúrbio hipermelanótico comum, que afeta a face e está associado a consideráveis impactos psicológicos. O manejo do melasma é desafiador e requer um plano de tratamento a longo prazo, onde a terapia tópica é a base do tratamento. $O$ objetivo desta pesquisa é apresentar uma revisão com ácidos tópicos mais indicados e utilizados como tratamento para melasma em locais com clima tropical Trata-se de uma revisão integrativa de literatura, com busca de publicações entre os anos de 2009 a 2020 e apresentar a evolução de tratamentos neste período. Foi possível observar que estão disponíveis várias opções de tratamento tópico, das quais a hidroquinona (HQ) é o agente mais prescrito, e entre outros agentes tópicos para os quais existem vários graus de evidência de eficácia clínica incluem o ácido azelaico, ácido kojic, retinóides, esteróides tópicos, ácido glicólico, mequinol e arbutina e ácido tranexâmico. A terapia combinada é o modo de tratamento preferido para o sinergismo e a redução de efeitos indesejáveis.

Palavras-chave: Estética. Hidroquinona. Melasma. Tratamento.

\section{ABSTRACT}

Melasma is a common hypermelanotic disorder, which affects the face and is associated with considerable psychological impacts. The management of melasma is challenging and requires a long-term treatment plan, where topical therapy is the basis of treatment. The objective of this research is to present a review with topical acids most indicated and used as a treatment for melasma in places with tropical climate. It is an integrative literature review, with a search for publications between the years 2009 to 2020 and to present the evolution of treatments in this period. It was possible to observe that several topical treatment options are available, of which hydroquinone $(\mathrm{HQ})$ is the most prescribed agent, and among other topical agents for which there are varying degrees of evidence of clinical efficacy include azelaic acid, kojic acid, retinoids, topical steroids, glycolic acid, mequinol and arbutin and tranexamic acid. Combination therapy is the preferred mode of treatment for synergism and the reduction of undesirable effects.
1 Enfermeira. Pós Graduanda em Saúde Estética pela IEES, Palmas-TO.

E-mail:

allyneresplande@gmail.com

2 Enfermeira. Pós Graduanda em Saúde Estética pela IEES, Palmas-TO.

E-mail:

moraisd298@gmail.com

3 Enfermeira. Orientadora. Especialista em Enfermagem estética pela Faculdade Batista-MG. Docente da Universidade de Gurupi UnirG, Gurupi-TO.

E-mail:

enf.elainemayra@hotmail.com

3 Fisioterapeuta. Mestre em Ciências da Saúde pela UFT. Palmas-TO. Docente da Universidade de Gurupi UnirG, Gurupi-TO.

\section{Email:}

saviaherrera@gmail.com

Keywords: Aesthetics. Hydroquinone. Melasma. Treatment. 


\section{INTRODUÇĀO}

Melasma é uma hipermelanose adquirida caracterizada pela presença de máculas irregulares, em geral bilaterais e simétricas, de cor acastanhada, que ocorrem em áreas de pele expostas à radiação ultravioleta, facilmente diagnosticada ao exame clinico porem, apresenta uma cronicidade, com recidivas frequentes. O nome melasma deriva do grego melas, significando negro. Cloasma é um termo usado com o mesmo sentido, sendo também derivado do grego cloazein, de: estar esverdeado usado para descrever o desenvolvimento do melasma durante a gravidez. ${ }^{13}$

A patogênese do melasma é complexa e ainda não é muito conhecida. Os fatores de risco conhecidos incluem predisposição genética, exposição à radiação ultravioleta (UV), fotótipo mais escuro (pele Fitzpatrick tipolll-IV-VI), influência hormonal (gravidez, contraceptivos orais, aumento dos níveis de hormônio luteinizante, doença da tireoide) e certos medicamentos, como a fenitoína, fotossensibilizadores e anticonvulsivantes. ${ }^{24}$

Entre as gestantes, a prevalência pode chegar a 70\% é geralmente melhora um ano após o parto, mas as áreas de hiperpigmentação podem nunca se resolver completamente. 5

As manchas predominam na face, em regiões malares, fronte, lábio superior, mento região mandibular, podendo acometer outras áreas, como a porção anterior do tórax e membros superiores com menor frequência. 67

O diagnostico é clínico, com a ajuda do exame da lâmpada de wood, o melasma pode ser classificado de acordo com a profundidade da deposição de pigmentos, como: epidérmico, dérmico, misto e inaparente. ${ }^{5}$

O Epidérmico a cor torna-se mais acentuada. Nesse tipo, a melanina está depositada na epiderme, nas camadas basais e suprabasal. No tipo dérmico a melanina está depositada na epiderme e na derme superficial e profunda, assim a pigmentação não é intensificada com a luz de Wood. Já o misto a luz de Wood intensifica a pigmentação em algumas áreas, enquanto outras permanecem inalteradas. $\mathrm{O}$ menos comum e $\mathrm{o}$ tipo inaparente onde as manchas, visíveis à luz do dia, tornam-se inaparentes à luz de Wood.

As melanodermias estão no topo das queixas relatadas nas consultas dermatológicas no Brasil, cuja representatividade no ranking ocupa o terceiro lugar $(8,4 \%)$ é um distúrbio comum que afeta milhões de pessoas em todo o mundo, com a prevalência exata variando entre $1,5 \%$ e $33,3 \%$, dependendo da população. ${ }^{216}$ 
O tratamento é amplamente indicado porque o melasma compromete a qualidade de vida das pessoas, sendo à base do tratamento a fotoproteção. ${ }^{16}$

Diversas modalidades de terapia medicamentosa têm sido utilizadas, como a hidroquinona $(\mathrm{HQ})$, que inibe a atividade da enzima tirosinase. Apesar de seus sérios efeitos adversos e resultados moderados em $80 \%$ dos pacientes, o $\mathrm{HQ}$ é acido mais prescrito para tratamento do melasma, sendo utilizada de forma segura, na concentração adequada e associada a outros agentes clareadores, tem eficácia comprovada no tratamento do melasma. Outros ácidos como o ácido tranexâmico mostram segurança e resultados eficazes no tratamento do melasma. 1216

Sendo assim a presente pesquisa tem como objetivo apresentar os principais tratamentos tópicos para o tratamento de melasma em clima tropical, além de descrever o melasma e sua fisiopatologia.

\section{MATERIAIS E METODOS}

Pesquisa de revisão integrativa da literatura realizada entre os meses de Fevereiro a Dezembro de 2020, com busca em livros e artigos publicados em revistas e jornais nas bases de dados: LILACS (Literatura Latino Americano e do Caribe em Ciências da Saúde), SciELO (Scientific Eletronic Library On-line), BIREME (Centro Latino-Americano e do Caribe de Informação em Ciências da Saúde).

Foram utilizados como descritores: "tratamento para melasma", e "hidroquinona" no tratamento de melasma. Foram encontrados 45 artigos no total.

Para a construção do estudo, os artigos apresentaram os critérios de inclusão: discorrer sobre o tema proposto e estarem disponíveis gratuitamente nas bases de dados para leitura na íntegra, produções científicas escritas em português publicadas no período de 2009 a 2019. Foram excluídos os artigos que não se adequavam à temática estudada. Ao fim desse processo de seleção, restaram 16 artigos para a análise do conteúdo.

Após essas etapas os artigos selecionados foram lidos integralmente para a realização deste trabalho e elaborado um quadro esquemático de cada artigo selecionado, respeitando os princípios éticos da pesquisa, citando as ideias principais de cada autor. 


\section{RESULTADOS}

Foram analisadas 16 literaturas, onde observou-se que a hidroquinona ainda é o tratamento tópico mais utilizado, porém diante de contraindicações e possíveis reações adversas, tem surgido novos protocolos de tratamento, como o uso do ácido tranexâmico, que traz ótimos resultados e poucos efeitos adversos, conforme pode-se observar na tabela abaixo:

Tabela 1 - Relação da busca de artigos obtidos com relação a tratamentos de melasma.

\begin{tabular}{|c|c|c|c|}
\hline Autores & Ano & Tipo de Estudo & Principais Resultados do Estudo \\
\hline Nascimento et al ${ }^{1}$ & 2019 & Revisão bibliográfica & $\begin{array}{l}\text { Tratamento de melasma durante } \\
\text { gravidez }\end{array}$ \\
\hline Barbosa; Guedes ${ }^{2}$ & 2018 & $\begin{array}{l}\text { Pesquisa qualitativa de cunho } \\
\text { exploratório-descritivo realizada em } \\
\text { periódicos internacionais no período } \\
\text { de novembro de } 2016 \text { a abril de } \\
2017 \text {. }\end{array}$ & $\begin{array}{l}\text { Demonstrar diversos tratamentos } \\
\text { desenvolvidos nos últimos anos }\end{array}$ \\
\hline Kraus; Lemos ${ }^{3}$ & 2019 & Revisão de literatura & $\begin{array}{l}\text { Tratamento de melasma durante } \\
\text { gravidez }\end{array}$ \\
\hline Medeiros et al ${ }^{4}$ & 2016 & $\begin{array}{l}\text { Estudo descritivo desenvolvido por } \\
\text { meio do relato de um experimento } \\
\text { clínico }\end{array}$ & $\begin{array}{l}\text { Tratamentos combinados para } \\
\text { melasma }\end{array}$ \\
\hline Souza et al ${ }^{5}$ & 2018 & Revisão literatura & $\begin{array}{l}\text { Tratamento associado com uso de } \\
\text { ácido kójico e glicólico no } \\
\text { tratamento do melasma }\end{array}$ \\
\hline Tamler et al ${ }^{6}$ & 2009 & $\begin{array}{l}\text { Análise de concordância entre os } \\
\text { dois métodos na classificação do mel } \\
\text { asma. }\end{array}$ & $\begin{array}{l}\text { Classificação do melasma através } \\
\text { da dermatoscopia e } \\
\text { à classificação sob a lâmpada } \\
\text { de Wood. }\end{array}$ \\
\hline Quintela; Pontes $^{7}$ & 2019 & $\begin{array}{l}\text { Estudo experimental, prospectivo, } \\
\text { simples-cego e randomizado }\end{array}$ & $\begin{array}{l}\text { Tratamentos de melasma e } \\
\text { reações adversas }\end{array}$ \\
\hline Ayres et al 8 & 2016 & Estudo prospectivo & $\begin{array}{l}\text { Melasma e tratamento com } \\
\text { hidroquinona }\end{array}$ \\
\hline Magalhães et al ${ }^{9}$ & 2010 & $\begin{array}{l}\text { Avaliação clínica, através do MASI, e } \\
\text { avaliação de impacto na qualidade } \\
\text { de vida }\end{array}$ & $\begin{array}{l}\text { Peeling de ácido láctico alia } \\
\text { efetividade no tratamento do } \\
\text { melasma }\end{array}$ \\
\hline Carmona $^{10}$ & 2014 & Pesquisa bibliográfica & $\begin{array}{l}\text { Melasma e tratamento com } \\
\text { hidroquinona }\end{array}$ \\
\hline Leite et al ${ }^{11}$ & 2016 & Prospecção tecnológica & $\begin{array}{l}\text { Retinóides no tratamento de } \\
\text { melasma }\end{array}$ \\
\hline Santana; Araújo ${ }^{12}$ & 2018 & Estudo prospectivo & $\begin{array}{l}\text { Uso de ácido glicólico no } \\
\text { tratamento de melasma }\end{array}$ \\
\hline $\begin{array}{l}\text { Silveiro; Castro; } \\
\text { Miranda } 13\end{array}$ & 2013 & $\begin{array}{l}\text { Avaliação da atividade antioxidante } \\
\text { pelo método do sequestro do radical } \\
\text { livre DPPH }\end{array}$ & $\begin{array}{l}\text { Novas substâncias } \\
\text { despigmentantes }\end{array}$ \\
\hline Leal; Lubia ${ }^{14}$ & 2011 & Revisão bibliográfica & $\begin{array}{l}\text { Tratamento associado de } \\
\text { hidroquinona e arbutin }\end{array}$ \\
\hline Silva RCVL,et al ${ }^{15}$ & 2015 & Revisão sistemática & $\begin{array}{l}\text { A utilização dos despigmentantes } \\
\text { no tratamento de melasma }\end{array}$ \\
\hline $\begin{array}{l}\text { Menezes, Priscila } \\
16\end{array}$ & 2018 & Livro: Dermatologia na Estética & $\begin{array}{l}\text { Tratamento de discromias com } \\
\text { ácidos trenexãmico e laser }\end{array}$ \\
\hline
\end{tabular}

Fonte: Autoras (2019).

Conforme observado nos estudos citados à maioria dos casos é tratada com agentes tópicos, usados isoladamente ou em combinações. Outras modalidades de tratamento 
utilizadas no tratamento desse distúrbio hipermelanótico são peelings químicos e terapias físicas na forma de vários lasers ou fontes de luz de pulso intenso. Todos os pacientes com melasma devem ser orientados sobre o curso natural da doença e a necessidade de adesão a um plano de tratamento a longo prazo. ${ }^{4}$

Uma história cuidadosa sobre os possíveis fatores precipitantes ou agravantes deve ser tomada com atenção especial à ingestão de contraceptivos orais ou outras preparações hormonais, medicamentos fototóxicos e anti-convulsivos e uso de cosméticos. Recomendase a interrupção das pílulas orais e a prevenção de cosméticos perfumados. A recorrência do melasma ocorre com a exposição à luz solar e outras fontes de raios ultravioletas. Medidas fotoprotetoras, como evitar a exposição direta ao sol e o uso regular de filtro solar de amplo espectro, são sempre recomendadas, embora não existam estudos clínicos sobre seu papel. ${ }^{4}$

O diagnóstico e clínico porem recursos como o exame da lâmpada de Wood auxilia na identificação do melasma. O exame da lâmpada de Wood não é benéfico em indivíduos muito escuros e esse tipo é classificado como indeterminado. ${ }^{367}$

O tratamento com agentes desmielanizantes deve ser continuado por vários meses antes que benefícios clínicos significativos se tornem visíveis. Os agentes tópicos são muito mais eficazes no tipo epidérmico de melasma. ${ }^{1}$

\section{DISCUSSÃO}

Através da análise detalhada dos estudos selecionados observou os apontamentos com relação ao tratamento do melasma em ambiente tropical, como é o caso do Brasil, que evidencia a ampla utilização de hidroquinona em concentrações que variam de 1,5\% a 5\% associada à fotoproteção para a manutenção do sucesso terapêutico.

Estudos novos apontam o Ácido Tranexâmico como seguro e eficaz, usado de forma tópica, cremes ou associado. Assim através deste estudo evidenciou os ácidos mais utilizados quando o assunto é tratamento e manutenção do melasma.

$O$ ideal e ter o conhecimento da Fisiopatologia do Melasma para elaborar estratégias que visam à supressão dos genes que causam o aumento da pigmentação. ${ }^{4}$ 


\subsubsection{Hidroquinona $(\mathrm{HQ})$}

A hidroquinona $(\mathrm{HQ})$, também conhecida como di-hidroxibenzeno, é um composto hidroxifenólico estruturalmente semelhante aos precursores da melanina que inibe a formação de melanina. ${ }^{1}$

O HQ afeta não apenas a formação, melanização e degradação dos melanossomos, mas também afeta as estruturas membranosas dos melanócitos e, eventualmente, causa necrose de melanócitos inteiros. O HQ é um agente oxidante que pode oxidar em tubos ou garrafas, mudando a cor de formulações do branco ao marrom. Os produtos que sofreram essa alteração de cor são ineficazes e devem ser descartados. ${ }^{5}$

$\mathrm{O} H Q$ é o agente despigmentante mais frequentemente prescrito em todo o mundo e permaneceu o padrão ouro para o tratamento do melasma, particularmente do tipo epidérmico. ${ }^{8}$ As preparações de HQ são comumente usadas no tratamento de melasma em concentrações variando de 5 a 10\%, aplicadas uma vez ao dia. Resultados variavelmente bons, porém reversíveis, são obtidos na maioria dos pacientes tratados com $\mathrm{HQ}$. Os efeitos despigmentantes do tratamento com $\mathrm{HQ}$, tornam-se evidentes após 5 á 7 semanas. $\mathrm{O}$ tratamento deve ser continuado por pelo menos três meses, até um ano. O HQ também é formulado em combinação com outros agentes, como filtros solares, esteróides tópicos, retinóides e ácidos glicólicos, para benefícios adicionais. ${ }^{9}$

As reações adversas do $\mathrm{HQ}$ estão relacionadas à sua dose e à duração do tratamento. Irritação é a complicação mais comum; outros efeitos adversos incluem eritema, picada, milião colóide, dermatite de contato irritante e alérgica, descoloração das unhas, hipocromia transitória e hipermelanose pós-inflamatória paradoxal. A chamada despigmentação semelhante a confete ou hipomelanose gutata é caracterizada por manchas despigmentadas que se desenvolvem nas máculas do melasma. ${ }^{10}$

A hidroquinona não deve ser usada em mulheres grávidas ou amamentando devido à sua caracterização de categoria C. ${ }^{5}$

\subsection{2 Ácido Azeláico}

O ácido azeláico, é derivado de $P$. Ovale, e é um inibidor competitivo reversível fraco da tirosinase. Possui ação antiproliferativa e é seletivamente citotóxico para melanócitos hiperativos, com efeitos mínimos na pele normalmente pigmentada. Está disponível em formulações a $20 \%$ de creme ou $15 \%$ de gel. Em vários estudos, ele foi associado à hidroquinona, com eficáciac comprovada, mas significativamente mais efeitos colaterais, 
como queima de eritema, prurido e descamação. Porém, sendo o mais indicado a gestantes do que hidroquinona conforme reiterado por Kraus e Lemos. ${ }^{1,2,3}$

\subsection{3 Ácido Retinóico}

O ácido retinóico é uma molécula derivada da vitamina $A$ e tem como função a dispersão dos grânulos de pigmento nos queratinócitos, interferência na transferência dos melanossomas e aceleração do turnover celular, aumentando a perda do pigmento, considerado um beta hidroxiácido superficial. ${ }^{16}$

O peeling de ácido retinóico é considerado superficial, pois atinge somente o estrato córneo, utilizado no tratamento do melasma, associado a outros protocolos para potencializar os seus benefícios e considerado ácido de fácil manejo e seguro para evitar efeitos adversos. ${ }^{11}$

\subsection{4 Ácido glicólico}

O ácido glicólico é um ácido alfa-hidroxi que geralmente é combinado com outros agentes a uma concentração de 5 a $10 \%$ por sua propriedade de clarear a pele. mecanismo de seu efeito pode ser devido à remodelação epidérmica e descamação acelerada, o que resultaria em rápida dispersão do pigmento nas lesões pigmentares. Também reduz diretamente a formação de melanina nos melanócitos pela inibição da tirosinase..$^{5,12}$

\subsection{5 Ácido Tranexâmico}

O ácido tranexâmico é uma droga hidrofílica inibidora da plasmina, utilizada como agente antifibrinolítico tem sido administrada como alternativa para o tratamento do melasma por apresentar, por meio do uso tópico, cápsulas por via oral, injeções intradérmicas a prevenção da pigmentação induzida por raios Ultravioleta (UV). ${ }^{1}$

Estudos atuais o apontam como uma forma de tratamento mais segura e eficaz, com um aumento significativo na durabilidade de clareamento e segurança, minimizando os efeitos colaterais quando comparado às outras formas de tratamento. ${ }^{16}$

\subsubsection{Outros Agentes Novos e Experimentais}

Vários agentes, sintéticos e derivados de fontes naturais, como Polypodium leucotomos, Ácido Ascórbico e o extrato de Uva-Ursi, foram investigados por seu papel 
potencial na redução da pigmentação da melanina. O Polypodium leucotomos é um ativo de uma planta da Costa Rica muita eficaz em proteger a pele dos raios UV. ${ }^{4}$

Dentre eles $\mathrm{o}$ ácido ascórbico tem propriedades antioxidantes e afeta a melanogênese, reduzindo a dopaquinona a DOPA e impedindo a produção de radicais livres e a absorção de radiação ultravioleta. Comparando a eficácia de ácido ascórbico a $5 \%$ e hidroquinona a $4 \%$ em 16 pacientes com melasma em dupla ocultação. ${ }^{13}$

Embora a hidroquinona demonstre uma resposta melhor, o ácido ascórbico pode desempenhar um papel na terapia do melasma, pois é quase desprovido de efeitos colaterais e pode ser usado sozinho ou em terapia combinada. $O$ ácido ascórbico (vitamina C) é relatado tratamento para melasma devido à sua capacidade de quelar íons cobre. Não funciona bem como monoterapia, é altamente instável e rapidamente oxidado. Pode ser um bom complemento de tratamento em pacientes que não toleram a hidroquinona, pois causa menos irritação. ${ }^{1}$

\subsubsection{Tratamento Combinado}

Os agentes tópicos atuam em diferentes estágios desse processo, fornecendo uma justificativa para combinações de agentes para melhor efeito terapêutico. Além de ter um efeito sinérgico, um medicamento específico pode revogar efeitos indesejáveis de outro medicamento formulado no mesmo veículo. Por exemplo, os esteróides tópicos podem reduzir os efeitos irritantes do $\mathrm{HQ}$ ou dos retinóides. Por outro lado, os retinóides podem prevenir a atrofia cutânea induzida por esteroide. ${ }^{14}$

Muitas combinações de diferentes agentes tópicos foram estudadas e muitas são comercializadas por empresas farmacêuticas. A hidroquinona é geralmente o principal componente das formulações. É combinado com medicamentos como ácido glicólico, ácido azelaico, ácido kojic (que é um 5-hidroxi-2-metil-4,4-Piranhona), sendo uma micotoxina quelante da tirosinase, que também impede a síntese de melanina, e ácido retinóico ou corticosteroides. $.^{1},{ }^{5}$

Além disso, comercializam-se misturas arbitrárias de outros agentes desmielanizantes, embora a eficácia e a segurança não tenham sido estabelecidas por ensaios clínicos controlados para a maioria deles. No entanto, a combinação mais amplamente estudada e utilizada é a chamada 'combinação tripla', uma formulação contendo $\mathrm{HQ}$, ácido retinóico e corticosteroides. ${ }^{8}$

Certos agentes despigmentantes têm sido utilizados para o tratamento do melasma, dentre os quais a hidroquinona tem sido a mais amplamente utilizada devido à sua eficácia 
e segurança no uso a curto prazo, conforme descreveu Nascimento et $a^{1}{ }^{1}$ o ácido ascórbico, hidroquinona e extrato de uva - ursina.

No entanto, a hidroquinona é recentemente relatada como sendo um composto citotóxico e mutagênico em células de mamíferos e, portanto, é proibida em vários países. $\mathrm{E}$, isso tem ocasionado busca por novos agentes despigmentantes alternativos para 0 tratamento do melasma nos últimos anos, conforme descrito por Hein e Araújo ${ }^{15}$ em seu estudo.

Os peelings químicos geralmente são recomendados para pacientes que não respondem aos tratamentos clareadores da pele e mostram resultados mistos para 0 tratamento com melasma. Existem três tipos de peelings químicos: superficial, médio e profundo (mais efeitos adversos ocorrem com peelings mais profundos). Eles são usados principalmente em caucasianos e são mais úteis no tratamento de melasma do tipo epidérmico, embora as recorrências sejam frequentes. Em pacientes com tipos de pele mais escuros, existe o risco de Hiperpigmentação Inflamatória. ${ }^{12}$

Existem várias formulações, como os peeling de ácido láctico que demonstra ser eficaz e seguro no tratamento do melasma com monoterapia. ${ }^{9}$

Estudos como o de Medeiros et $\mathrm{al}^{4}$, também relatam a boa eficácia da laserterapia no tratamento do melasma. Os principais efeitos adversos são eritema, queimação, secura, descamação, edema, hiperpigmentações rebote, hipopigmentações, despigmentações, urticária física, erupção acneiforme, petéquias e reativação do herpes simples.

De uma perspectiva histórica, os agentes comumente usados para o tratamento do melasma incluem hidroquinona, ácido azelaico, ácido kojic, ácido glicólico, ácido salicílico, tretinoína e o ácido tranexâmico. Desses tratamentos, a hidroquinona é a mais utilizada, porem estudos sugerem que as formulações combinadas oferecem os melhores resultados. ${ }^{3,5}$

A hidroquinona inibe a tirosinase, que é a enzima limitadora da taxa de produção de pigmentos, e é bem tolerada na maioria dos pacientes. O efeito colateral mais comum é dermatite de contato irritante. ${ }^{1}$

Os tratamentos de segunda linha, como peelings e lasers químicos, são eficazes em alguns pacientes, mas essas abordagens podem estar associadas a complicações agudas e de longo prazo, principalmente em indivíduos com tipos de pele mais escuros. ${ }^{4,7,9,12}$

O tratamento do melasma deve incluir uma abordagem multimodalidade que incorpore agentes fotoprotetores, tratamentos antioxidantes, clareadores da pele, esfoliantes e procedimentos de recapeamento, conforme necessário. 4, 6,15. 
As intervenções terapêuticas para o melasma incluem uma abordagem multimodal incorporando agentes de fotoproteção, clareadores tópicos e orais da pele e procedimentos de recapeamento. ${ }^{10}$

A fotoproteção diária é fundamental no tratamento desse distúrbio terapeuticamente desafiador e de recaída universal. O uso de filtros solares de amplo espectro é essencial. Cuidadores de pacientes com melasma geralmente relatam a ocorrência comum de recidivas rápidas e frequentes após exposição intensa a UV. ${ }^{4}$

Apesar das inúmeras modalidades de tratamento disponíveis, devido ao seu curso crônico e recorrente, o tratamento do melasma ainda permanece um desafio. Embora a hidroquinona e os cremes de combinação tripla continuem sendo os mais utilizados para o tratamento, preocupações de segurança a longo prazo e possíveis efeitos colaterais justificam a investigação de novas modalidades de tratamento mais eficazes e seguras. ${ }^{8,11,13,14}$

O melasma permanece uma condição crônica, terapeuticamente desafiadora e universalmente recorrente. Esse distúrbio psicologicamente devastador deve ser tratado com uma abordagem multimodalidade que incorpore agentes fotoprotetores, tratamentos antioxidantes, clareadores de pele, esfoliantes e procedimentos de recapeamento em casos graves. Uma infinidade de novas terapias orais, tópicas e combinadas para melasma foram introduzidas para expandir nosso repertório de terapias e justificar ensaios adicionais para comprovar sua eficácia e segurança.

\section{CONSIDERAÇÓES FINAIS}

Observou-se que o gerenciamento do melasma pode ser desafiador e requer tratamento a longo prazo com agentes tópicos. Os resultados geralmente são insatisfatórios e, por vezes, agentes tópicos podem causar reações adversas significativas. A hidroquinona permaneceu como o tratamento tópico mais utilizado, mas as preocupações com seus efeitos colaterais permanecem. Sugere-se que uma combinação tripla de hidroquinona, ácido retinóico e corticosteróide seja o tratamento tópico de primeira linha para esse distúrbio pigmentar.

O ácido tranexâmico vem como um potencial tratamento para o melasma, com melhores resultados e poucos efeitos adversos.

Muitos novos agentes que inibem a melanogênese foram desenvolvidos. Embora estudos experimentais in vivo e in vitro tenham sugerido seu papel potencial no manejo do 
melasma, os ensaios clínicos controlados são inexistentes e são urgentemente necessários no futuro.

\section{REFERÉNCIAS}

1. Nascimento DB, Fernandes IV, Figueiredo SS, Rosário KD do, Álvares A da CM. Etiologia e tratamento medicamentoso de melasmas durante a gestação. Rev. Inic. Cient. E-t [Internet]. 2019; 2(3):176-80. [acesso em 15 fev. 2020]. Disponível em: https://revistasfacesa.senaaires.com.br/index.php/iniciacao-cientifica/article/view/252/194.

2. Barbosa KL, Guedes MRB. Tratamento e suas implicações. Ciências Farmacêuticas. 2018; 30(2):85-94.

3. Kraus EA, Lemos F. Abordagem terapêutica do melasma no período gestacional: revisão de literatura. Artigo [graduação]. Costemologia e estética. Universidade do Sul de Santa Catarina, UNISUL, 2019.

4. Medeiros JKG; Neves WW; Moura NM; Medina WSG. Combinação terapêutica no tratamento do melasma. Cuidarte Enfermagem. 2016, jul-dez; 10(2):180-218.

5. Souza LC, Amurim NP, Grignolli LCME. O uso associado do ácido kójico e ácido glicólico como alternativa à hidroquinona no tratamento de melasma. Revista Científica Multidisciplinar Núcleo do Conhecimento. 2018; 1(2):49-68.

6. Tamler C, Fonseca RMR, Pereira FBC, Barcauí CP. Classificação do melasma pela dermatoscopia: estudo comparativo com lâmpada de Wood. Surgical \& Cosmetic Dermatology 2009;1(3):11-16.

7. Quintela JS, Pontes, RB. Terapia funcional despigmentante associada ao home care versus terapia isolada no tratamento do melasma. Graduação em estética [Internet]. 2019; Vol.17, no. 2: 1-23. [acesso em 15 mai. 2020]; Disponível em: http://www.repositorio.ufc.br/bitstream/riufc/48729/1/2019_art_jsquintela.pdf

8. Ayres EL, Costa A, Jorge ACF, Gonçalves Junior JE, Szrajbman M, Sant'Anna B. Estudo monocêntrico, prospectivo para avaliar a eficácia e a tolerabilidade de formulação cosmecêutica em pacientes com melasma. Surgical \& Cosmetic Dermatology. 2016; 8(3): 232-240.

9. Magalhães GM, Borges MFM, Oliveira PJV, Neves DR. Peeling de ácido láctico no tratamento do melasma: avaliação clínica e impacto na qualidade de vida. Surg Cosmet Dermatol. 2010;2(3):173-179.

10. Carmona L. Efeitos adversos causados pelo uso tópico da Hidroquinona [Internet]. Copyright; 2014 [acesso em 15 mar. 2020]. Disponível em: https://maistopestetica.com.br/wp-content/uploads/2020/06/Ebook-hidroquinona.pdf 
11. Leite MF, Viana EB, Pereira GRS, Andrade ACD, Amaral JG. Prospecção tecnológica sobre 0 uso de retinóides sem formulações despigmentantes. Cad. Prospec., Salvador. 2016; 8(4):681-687.

12. Santana GLS, Araújo JBB. O uso do ácido glicólico no tratamento do melasma. Rev. Conexão Eletrônica. Três Lagoas. 2018; 15(1):524-529.

13. Silveiro MDO, Castro CFS, Miranda AR. Avaliação da atividade antioxidante e inibitória da tirosinase das folhas de Dipteryx Alata Vogel (Baru). Rev. Bras. Plantas Med. Botucatu. 2013; 15(1):1-9.

14. Leal GF, Lubia N. O uso da hidroquinona e do arbutin para o tratamento do melasma: uma revisão bibliográfica. Artigo [Graduação]. Tecnologia em Estética e Imagem Pessoal. Universidade Tuitui do Paraná. 2011. [acesso em 15 fev 2020]. Disponível em: https://tcconline.utp.br/media/tcc/2017/05/uso-da-hidroquinona-e-do-arbutin-para-otratamento-do-melasma-uma-revisao-bibliografica.pdf

15. Silva RCVL, Holanda ES, Santos LCR et al. A utilização dos despigmentantes no tratamento de melasmas: uma revisão sistemática. Revista Interdisciplinar de Ciências Médicas [Internet]. 2014; [acesso em 15 abr. 2020]. Disponível em: https://docplayer.com.br/111205077-A-utilizacao-dos-despigmentantes-no-tratamento-demelasmas-uma-revisao-sistematica.html

16. Menezes, PFC. Aplicação da luz na dermatologia e estética. $2^{\circ}$ ed. São Carlos: Compacta; 2018. 